\title{
A Post-Installed Subsea Monitoring System for Structural and Flow Assurance Evaluation
}

\author{
David Brower \\ Astro Technology \\ Alexis Brower \\ Astro Technology \\ John Hedengren \\ Brigham Young University, john.hedengren@byu.edu \\ Reza Asgharzadeh Shishavan \\ Brigham Young University \\ Follow this and additional works at: https://scholarsarchive.byu.edu/facpub \\ Part of the Chemical Engineering Commons
}

\section{Original Publication Citation}

Brower, David V., et al. "A Post-Installed Subsea Monitoring System for Structural and Flow Assurance Evaluation." Offshore Technology Conference. Offshore Technology Conference, 2014.

\section{BYU ScholarsArchive Citation}

Brower, David; Brower, Alexis; Hedengren, John; and Asgharzadeh Shishavan, Reza, "A Post-Installed Subsea Monitoring System for Structural and Flow Assurance Evaluation" (2014). Faculty Publications. 1696.

https://scholarsarchive.byu.edu/facpub/1696

This Peer-Reviewed Article is brought to you for free and open access by BYU ScholarsArchive. It has been accepted for inclusion in Faculty Publications by an authorized administrator of BYU ScholarsArchive. For more information, please contact ellen_amatangelo@byu.edu. 


\title{
OTC 25368
}

\author{
A Post-Installed Subsea Monitoring System for Structural and Flow \\ Assurance Evaluation \\ D.V. Brower, A.D. Brower, Astro Technology Inc. \\ J.D. Hedengren, R. Asgharzadeh Shishavan, Brigham Young University
}

Copyright 2014, Offshore Technology Conference

This paper was prepared for presentation at the Offshore Technology Conference held in Houston, Texas, USA, 5-8 May 2014.

This paper was selected for presentation by an OTC program committee following review of information contained in an abstract submitted by the author(s). Contents of the paper have not been reviewed by the Offshore Technology Conference and are subject to correction by the author(s). The material does not necessarily reflect any position of the Offshore Technology Conference, its officers, or members. Electronic reproduction, distribution, or storage of any part of this paper without the written consent of the Offshore Technology Conference is prohibited. Permission to reproduce in print is restricted to an abstract of not more than 300 words; illustrations may not be copied. The abstract must contain conspicuous acknowledgment of OTC copyright.

\section{Abstract}

This paper describes major advancements for deploying sensing systems on existing subsea structures as part of the Clear Gulf study. In the past, a major shortcoming of post-installed monitoring systems has been poor coupling between the sensor and structure; this study provided methods to overcome this problem. Both subsea field testing and laboratory testing were performed to verify these advancements. The Clear Gulf study is a collaboration between the offshore energy industry and NASA with the goals of risk mitigation, safety, efficiency and environmental concerns in the offshore energy industry. The study is ongoing and has investigated new methods to improve deepwater monitoring and addresses installation of advanced sensors on already-deployed risers, flowlines, trees, and other subsea assets. These highly sensitive monitoring systems will provide operators a cost-effective method for detecting and responding to potential failures, flow assurance issues, and catastrophic events.

A significant achievement was recently made in bonding methods in subsea environments. Prior to installation on Tension Leg Platforms (TLPs), subscale test articles were fabricated and tested. There was a slight decrease in bonding strength, however, the methods demonstrated adequate adhesion for structural coupling integrity on subsea components. Aging tests were conducted to ensure long-term service life potential.

Full-scale implementation was accomplished on two TLPs in West Africa. Two challenges in calibration of the post installed sensors are determining the baseline or zero state of stress and sensitivity of the fiber Bragg gratings on the clamp to actual load changes on the structure. The effectiveness of the monitoring system was enhanced by calibration methods employing fundamental predictive methods to establish both baseline and sensitivity values. The transition layer between surface and deep water levels (thermocline) required temperature compensation of the strain sensors. Vastly changing temperature profiles were measured and analyzed at this moving boundary. A method to isolate temperature effects from structural data was developed and integrated into the software algorithm. A multiplexing method was incorporated with minimum cabling and connectors to make the system redundant and fault-tolerant to inadvertent cable damage. With this unique design, severing the cable in one location leads to no loss of data.

\section{Introduction}

Clear Gulf is a collaboration to increase productivity, boost safety and lessen environmental impact in the offshore energy industry. The project focuses on advancing fiber-optic technology to vastly improve monitoring of deepwater systems. It is led by Astro Technology, which pioneered the industry's use of fiber-optic sensors. Clear Gulf has drawn strong support from NASA and the U.S. House Energy \& Commerce Committee, and industry leaders are currently being invited to participate in this joint industry project. The objectives of the project are to combine the direction of regulators, the expertise from the space industry to operate safely in remote and harsh environments, and the grand challenges from the oil and gas industry. The objectives are specifically for:

- Stronger performance: Increase efficiency, reduce asset damage, improve field design, and mitigate environmental risk

- Operational improvements: Monitoring creates a safer work environment as operations move into deeper waters with more hazardous conditions

- Collaboration and innovation: Bring together experts from NASA and private industry to forge new solutions 
- Environmental safety: Advanced monitoring detects anomalous events, flow properties, equipment fatigue, and leaks in real time with unprecedented accuracy

Participants in the Clear Gulf study play a key role in further developing technology with the potential to transform offshore operations. In addition to enhancing safety and productivity, Clear Gulf fosters good will with government, the media and the public. Solutions are guided to ensure that technical and feasible options exist and that the regulators know how to apply the best available technology to meet current pressing challenges. Another key objective of the Clear Gulf study is to help members by aware of comprehensive monitoring solutions for platforms, risers, flowlines, subsea equipment, deepwater wells, and downhole operations. The center also fosters opportunities to interact with NASA and Congressional leaders on priority issues for the industry. By taking a proactive approach to monitoring solutions, member make reputational gains from playing a leading role in a high-profile project that proactively addresses safety and environmental concerns. In addition to meeting regulatory and environmental requirements, the improved monitoring targets reduced costs in the long term due to avoidance of spills, improved risk mitigation, and a long-term competitive advantage. The focus of this work is to foster technical solutions that are known to be the best practices for the industry in monitoring and proactive risk mitigation.

Fiber-optic sensors are akin to a central nervous system to provide reliable measurements while withstanding the most severe conditions. First developed to measure conditions inside solid rocket motors, this technology has proved to have enormous application in the oil and gas industry (1-4). By offering a more effective way to detect and respond to potential failures, advanced sensors prevent probems before they occur.

While Clear Gulf is ongoing, it is producing milestones for the industry. Recently a first-of-its-kind fiber-optic monitoring system was installed on two oil platforms off the coast of West Africa (5-6). Replacing the traditional load cell Tendon Tension Monitoring System (TTMS), this innovative technology is equivalent to moving from analog to high-speed internet, offering far greater speed, accuracy and reliability. Upon sensing any stresses along the tendon legs, the system transmits data topside in real time, enabling operators to make immediate adjustments. Clear Gulf is developing additional sensing technology for deepwater application that companies may seek to install in the future. Examples include advanced monitoring on pipelines, wells, mooring lines, hydrate formation, wax build-up, and leak detection (7-8). The nine specific tasks of the joint industry project are listed below and cover several critical areas for subsea systems and monitoring solutions.

\section{Clear Gulf Joint Industry Project Tasks}

1. Riser/flowline monitoring

2. Flow assurance

3. Additional subsea equipment monitoring

4. Miniature subsea robotics

5. Leak detection

6. Smart fields (Intelli-Fields)

7. Downhole monitoring

8. Mooring line monitoring

9. Arctic monitoring

A Technical Steering Committee is being assembled to lead Clear Gulf with representation from NASA, Congress and private industry. Participation helps shape the project, demonstrate leadership, work with other leaders across sectors, and benefit from positive press coverage. The Techincal Steering Committee meets to provide input on the tasks and prioritize development needs. Specific plans are currently under development and progress has been made on many of the areas. The task list also includes a thrust area for arctic studies to meet the emerging challenges in this environment. Additional details on Task 9: Arctic Monitoring is provided as an example of the plans that are currently under development as part of Clear Gulf.

\section{Task 9: Arctic Monitoring}

There are significant deposits of oil and gas in the Arctic - a recent USGS study estimates that $13 \%$ of the world's undiscovered oil and $30 \%$ of its undiscovered natural gas lie beneath the Arctic Ocean (9). However, safely and economically extracting these resources to meet the growing world-wide demand for energy is an unmet challenge, for although major oil and gas companies have been drilling exploratory wells in the Arctic Ocean for some time, they have yet to develop these essential capabilities:

- Adequate oil spill preparedness including cooperation among multiple operators so that environmental impacts of spills can be minimized. 
- The ability to bring resources to market in a relative short time (currently, it takes a decade or more to bring oil to market after it is discovered).

- Successful exploration operations within the short drilling season (e.g., July to October in the Chukchi and Beaufort Sea).

- Ocean drilling equipment that can withstand impacts from ice flows and freezing temperatures without damaging fragile marine ecosystems.

- The ability to meet strict government and tribal regulations associated with energy resource development.

Significant technological advances are needed to enable these capabilities. The goal of the proposed task is to help create those capabilities by catalyzing the development of:

1. Drilling structures (containment covers, tow lines, drilling rigs, etc.) that can withstand the harsh Arctic Ocean environment.

2. Risers for drilling rigs made of composites for reduced weight and improved efficiency.

3. High-performance computing, advanced software and analytics and better imaging technologies.

4. Sensors for locating oil and gas resources and monitoring drilling and production operations.

5. Reliable subsea equipment.

Each participating institution in the study has ongoing research that can be leveraged and tailored to develop Arctic drilling technologies. This task identifies technologies that can be developed to a level of technology readiness sufficient for industry partners to mature into operational systems. The team applies the expertise and research tools to develop these technologies.

\section{Current Progress on Clear Gulf Tasks}

Besides Arctic engineering, a description of the progress is given on clamp design, subsea bonding, and accelerated aging tests for adhesion strength verification. A case study with an actual installation on a West Aftica Tension Leg Platform (TLP) is provided with details on the installation, calibration, and performance.

\section{Clamp Design for Diver or ROV Installable Sensors}

An essential component of the Clear Gulf study is to address methods for coupling of sensors to subsea equipment. These installable sensors must meet several requirements to be suitable for the harsh and remote environmental conditions that are typical in the upstream industry. A current approach is to design clamps that can be placed around flowlines, tendons, mooring lines, risers, and at the well-head. These clamps are designed so that divers or remotely operated vehicles (ROVs) can handle and install the devices and secure the necessary cabling for topside data streaming. These installable clamps are ruggedized to both protect the sensor and secure the coupling to the structure. Figure 1 is a diagram of a clamp design for a 4-inch outter diameter riser. 


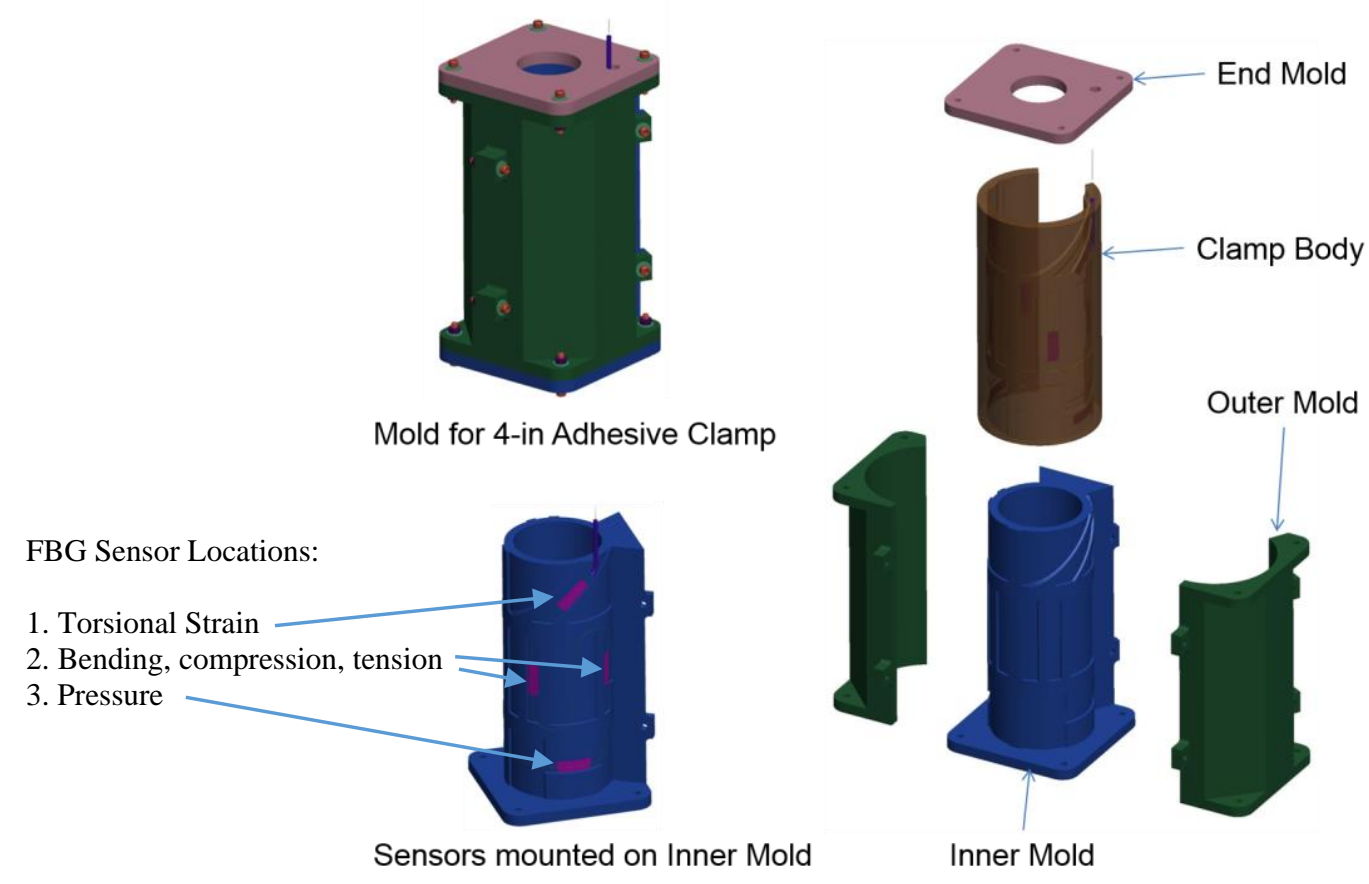

Figure 1. Mold Design for an Adhesive Clamp.

The inner mold has the fiber Bragg gratting (FBG) sensor locations selected to detect a number of relevant measurements on a typical riser. For example, one sensor at the bottom is placed to detect hoop strain. Internal pressure of the riser can be determined by measuring the slight expansion (strain) on the outer diameter of the pipe with this sensor. The four sensors placed in the direction of axial strain are depicted by the two sensors with vertical orientation. These sensors are separated by $90^{\circ}$ to detect all bending, compression, and tension simultaneously. This is important for the detection and mitigation of vortex induced vibration (VIV). If multiple sensor clamps are installed on the riser, bending modes can also be determined by combining the sensor readings at the distributed locations. The final sensor placement is shown with the top sensor that is placed diagonally with respect to the axial orientation of the riser. This sensor is used to sense torsional strain induced by the rotation of the riser or platform. Once the sensors are secured to the inner mold, the clamp body is cast from polyurethane, filling the space between the inner and outer mold. Figure 2 shows an 8 " actual mold that was created by 3-D printing of the model design.

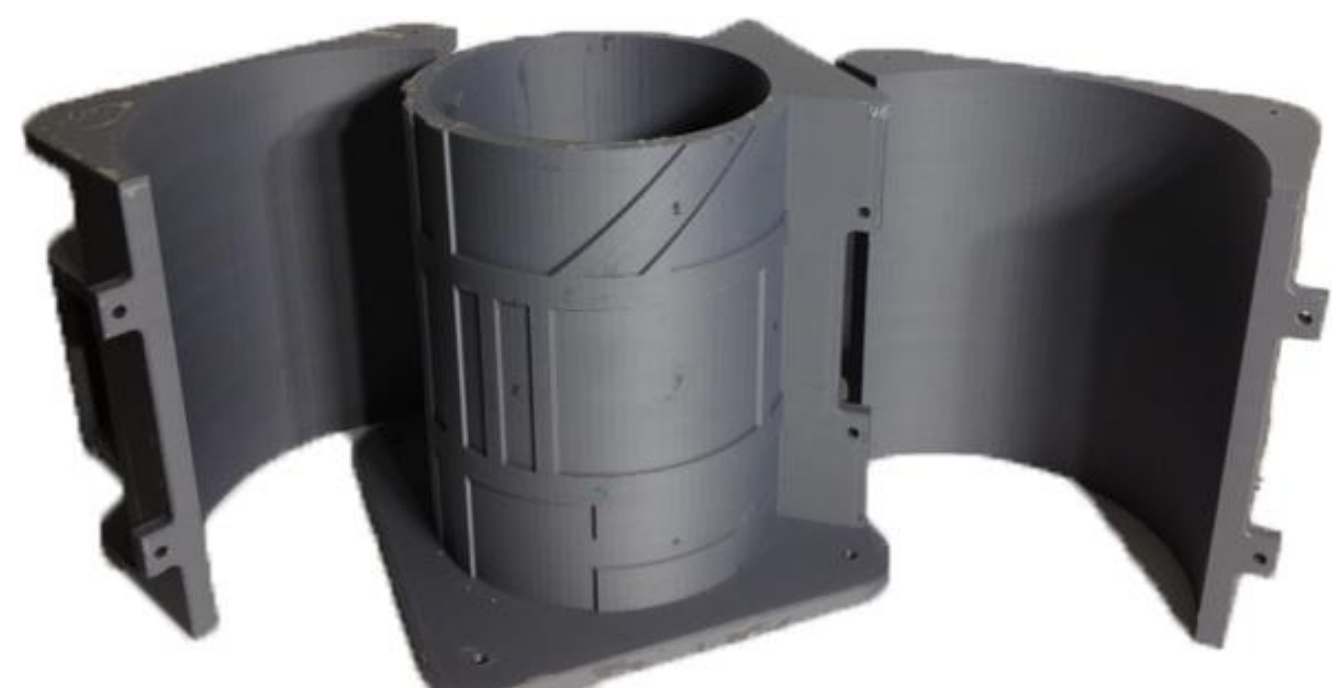

Figure 2. Mold for Clamp Fabrication Created by 3-D Printing.

The creation of the clamp was accelerated by the use of 3-D printing technology. A unique aspect of this clamp design is the design on the inner mold that creates both areas for sensor attachment as well as flow channels to ensure the adequate spreading of epoxy. The 3-D printing technology also enables rapid prototyping of other fixture devices propsed in the Clear Gulf study. This particular clamp design was printed at the NASA Johnson Space Center in Houston. Additional clamps are 
currently under production for the adhesion strength verification with age accelerated tests on sample pipes segments including 4-in, 8-in, and 24-in clamp designs as shown in Figure 3.

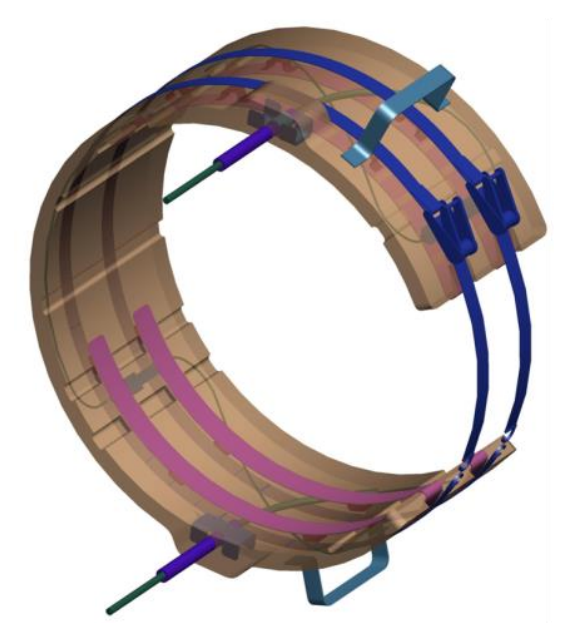

24-in Adhesive Clamp

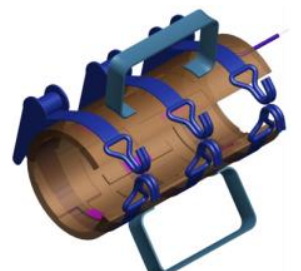

4-in Adhesive Clamp

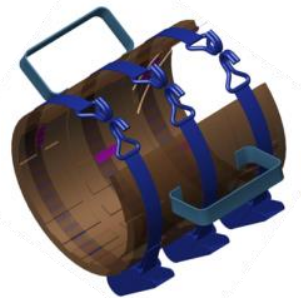

8-in Adhesive Clamp

Figure 3. Three clamp deisgns including 24-in, 4-in, and 8-in for various risers, flowlines and tendons.

The 24-in adhesive clamp was used on the tendons of the TLP in West Africa and additional details on the success of this are related below. The 4-in and 8-in clamps would primarily be used for riser monitoring but this has been limited to laboratory testing at this point. One of the drawbacks of the current adhesion method for securing clamps to subsea structures is that the epoxy must be applied top-side and the device installed within approximately 15 minutes before the epoxy cures and hardens. Additional research is currently underway to tailor the epoxy setup time or apply the epoxy in subsea environments. However, the current capabilities of the expoxy may be prohibitive for deepwater devices where it may require additional time to descend and maneuver the clamp into place. Another potential clamp device is the friction clamp as shown in Figure 4.

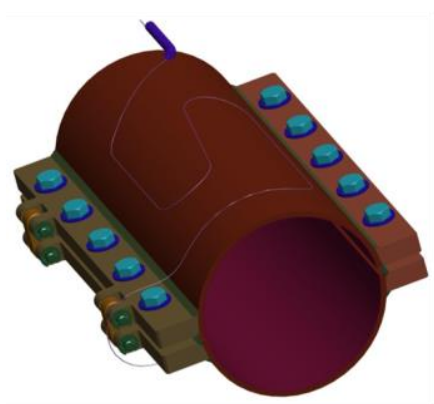

4-in Friction Clamp

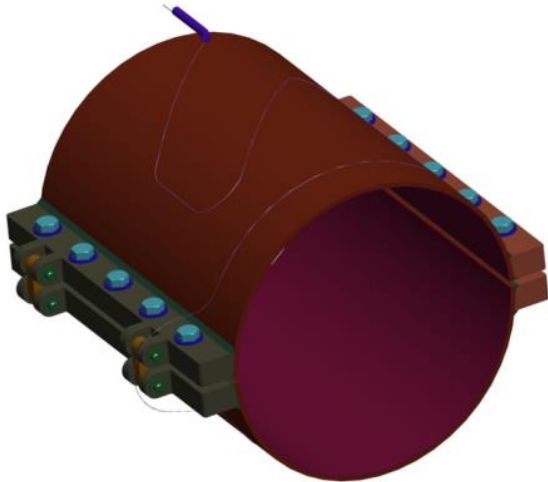

8-in Friction Clamp

Figure 4. Friction Clamp Design for Deepwater Application Where Adhesive Clamps are Not Feasible.

A design similar to the friction clamp was deployed on a deepwater subsea tie-back at a depth of 7,000 feet and 56 miles from the platform in the Gulf of Mexico. This earlier monitoring system provided the baseline for this new advanced system and was necessitated because one of the pre-installed sensor stations was damaged during installation. More than six years of data have been obtained and the system is still in operation (\#).

\section{Adhesion Testing for Subsea Coupling of Sensors to Structures}

One of the key issues with post-installed and non-intrusive sensing is the coupling between the sensor and the structure that is being monitored. Without adequate coupling or with delamination of the coupling, the sensors will degrade or fail over time. A key enabler for many of the sensing technologies in the Clear Gulf study is therefore adequate bonding to the structure over an extended period of time. Adequate bonding is enhanced through the results in this study where several types of exopy, clamp designs, accelerated aging conditions, and various bonding techniques are investigated to optimize this critical aspect of the sensing technology. 
The test conditions proposed in Appendix A are currently under evaluation. Each of the samples is brought to $75 \%$ of inelastic deformation or $0.15 \%$ strain (elastic deformation up to $0.20 \%$ strain). The samples are put under tension, compression, and in 4-point bending tests to simulate accelerated aging of the test articles and the coupling between the structure and sensor. The tensile strength is then measured by cutting button tabs in the polyurethane clamp and by attaching a pull tab as shown in Figure 5.

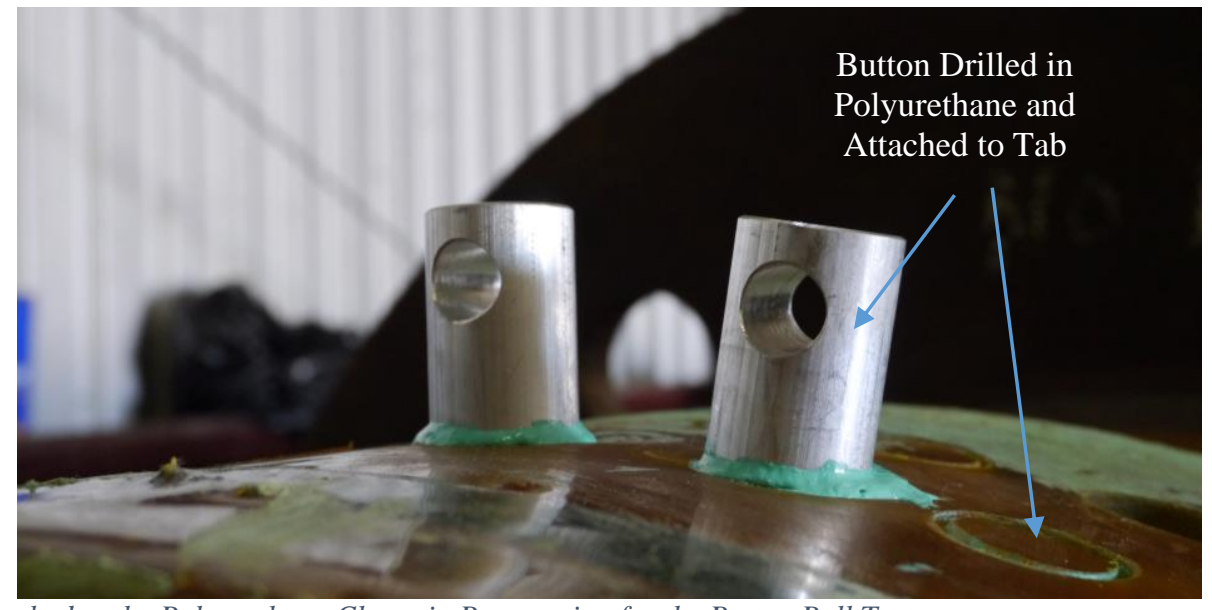

Figure 5. Pull Tabs Attached to the Polyurethane Clamp in Preparation for the Button Pull Test.

Once the aluminum tab is securely fastened to the button drilled out from the polyurethane, a mechanical lift device is attached to the aluminum tab. The lift device simultaneously applies a force upward and measures and records the applied force as shown in Figure 6. The peak pull force is detected and together with the area of the button, is used to calculate the tensile strength.

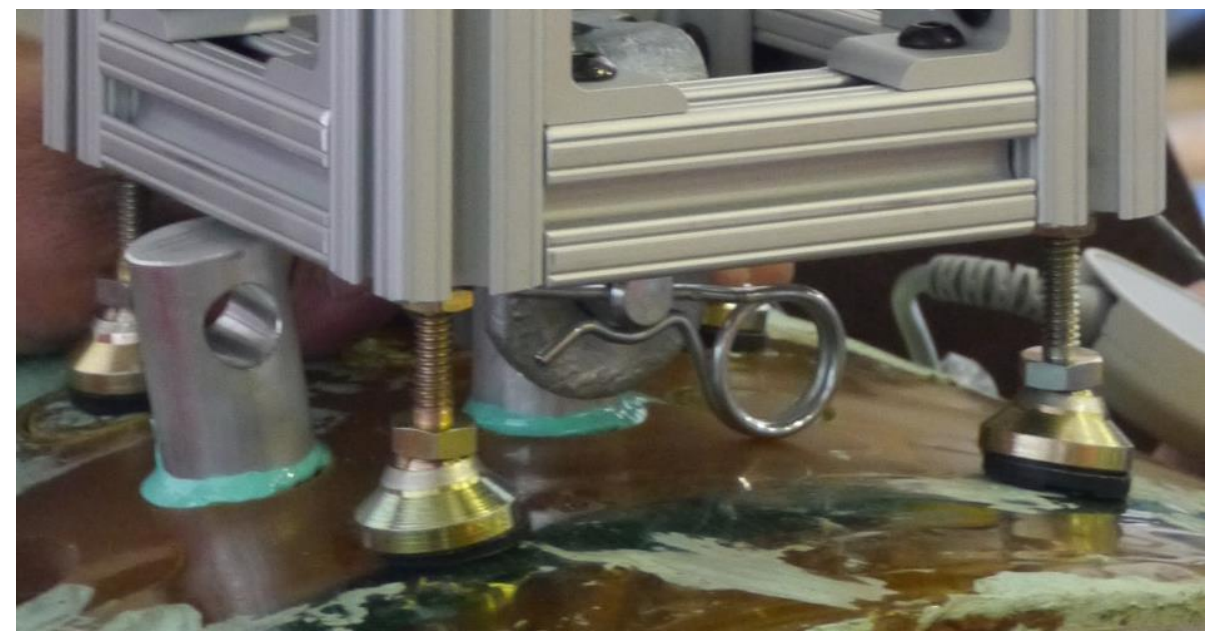

Figure 6. Device to Measure Tensile Strength of the Adhesive Clamp by Pulling the Button Tab to Failure.

Several wet and dry bonded samples were taken and subjected to accelerated aging tests. Predominate failure mode of the pull tests were mixed between failure of polyurethane and failure of the adhesive. Bare pipe metal resulted below the button when the failure mode was the adhesive while at other times the polyurethane failed and was the limiting factor for tensile strength. The number of tests, average, minimum, maximum, and standard deviation values for the button pull tests are shown in Table 1. 
Table 1: Tensile Strength Results for Button Pull Testing.

\begin{tabular}{|r|c|c|c|c|c|}
\hline & $\begin{array}{c}\text { Dry Bonded } \\
\text { Control }\end{array}$ & $\begin{array}{c}\text { Wet Bonded } \\
\text { Control }\end{array}$ & $\begin{array}{c}\text { 4-Point Bending } \\
\text { (Wet Bonding) }\end{array}$ & $\begin{array}{c}\text { Compression } \\
\text { (Wet Bonding) }\end{array}$ & $\begin{array}{c}\text { Tension (Wet } \\
\text { Bonding) }\end{array}$ \\
\hline Total Number of Test Conducted & 35 & 25 & 128 & 22 & 29 \\
\hline Number of Good Tests & 18 & 13 & 81 & 15 & 15 \\
\hline Number of Tab Break Tests & 17 & 11 & 39 & 2 & 5 \\
\hline Number of Bad Tests & 0 & 1 & 8 & 5 & 9 \\
\hline Min. Breaking Strength (psi) & 113.6 & 31.1 & 29.8 & 33.6 & 29.7 \\
\hline Max. Breaking Strength (psi) & 498.6 & 193.5 & 503.3 & 225.7 & 268.8 \\
\hline Average Breaking Strength (psi) & $\mathbf{2 9 2 . 0}$ & $\mathbf{8 1 . 4}$ & $\mathbf{1 3 6 . 2}$ & $\mathbf{1 1 4 . 0}$ & $\mathbf{1 0 5 . 3}$ \\
\hline Breaking Standard Deviation (psi) & 108.9 & 47.2 & 82.4 & 53.7 & 59.8 \\
\hline Predominate Failure Mode & Mixed & Steel Surface & Poly Surface & Steel Surface & Poly Surface \\
\hline
\end{tabular}

The button pull tests included a dry bonded control sample and a wet bonded that were attached after the accelerated aging tests. Additional results from the 4-point bending, compression, and tension tests are also shown. A couple observations from the test are that the wet bonding significantly decreases the tensile strength from an average of 292 psi to values in the range of 81-136 psi. This decrease in tensile strength is expected but the one surprising result is that the accelerated aging tests actually had a positive effect on tensile strength. This may have been due to the longer curing time for the wet bonded control or differences in preparation of the test articles. Although there was a slight increase, the main result from this study is that wet bonded adhesive clamps demonstrate adequate bonding strength for coupling sensors to risers, flowlines, tendons, or other structural surfaces.

\section{Case Study: Tendon Tension Monitoring System}

Encouraged by the success of the successful laboratory testing, full-scale implementation was accomplished on two TLPs in West Africa. The 24" inner diameter adhesive clamps were designed for attachment to four of eight tendons that secure the platform to the sea floor. The clamp design is shown in Figure 7 was cast with 8 FBG sensors including 4 temperature compensation sensors and 4 strain sensors at $90^{\circ}$ increments.
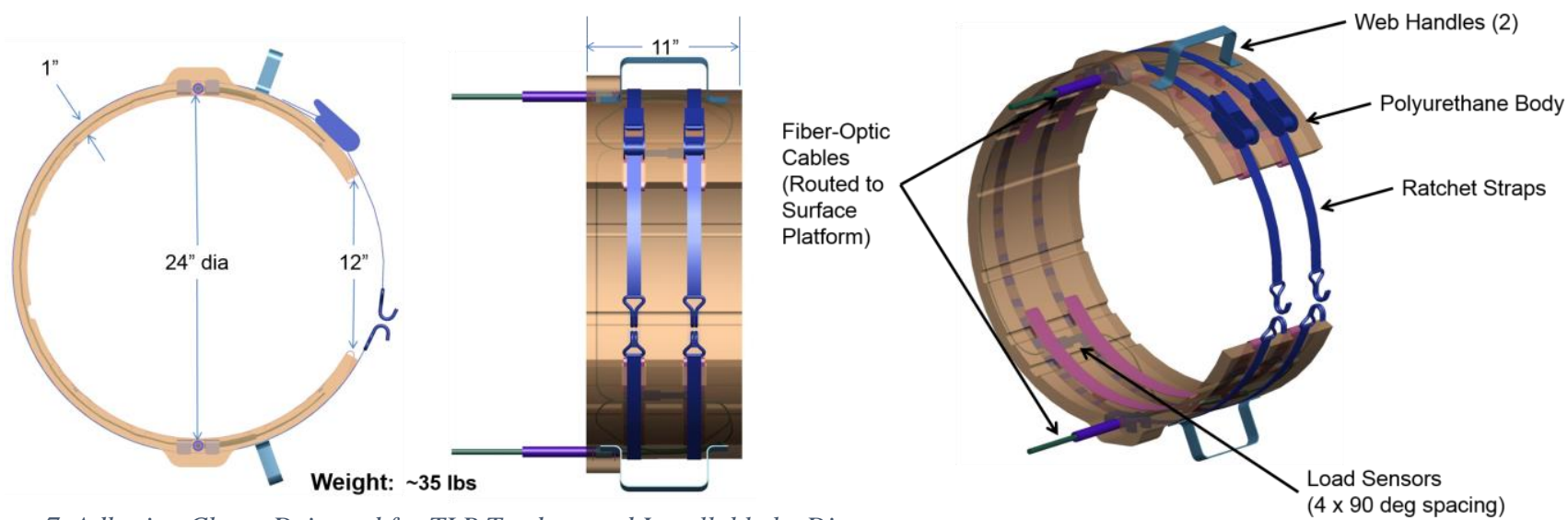

Figure 7. Adhesion Clamp Deisgned for TLP Tendons and Installable by Divers.

The fiber optic cables extend from an upper clamp installed at 60' depth below sea level to a lower clamp at $120^{\prime}$ depth below sea level. The clamps at two depths enable the detection of vortex induced vibration (VIV) and bending modes such as those due to current forces. After the clamps were fabricated and prepared for installation, the tendons were also prepared for installation by cleaning off the marine growth and polishing to a bare metal surface as shown in Figure 8 . 


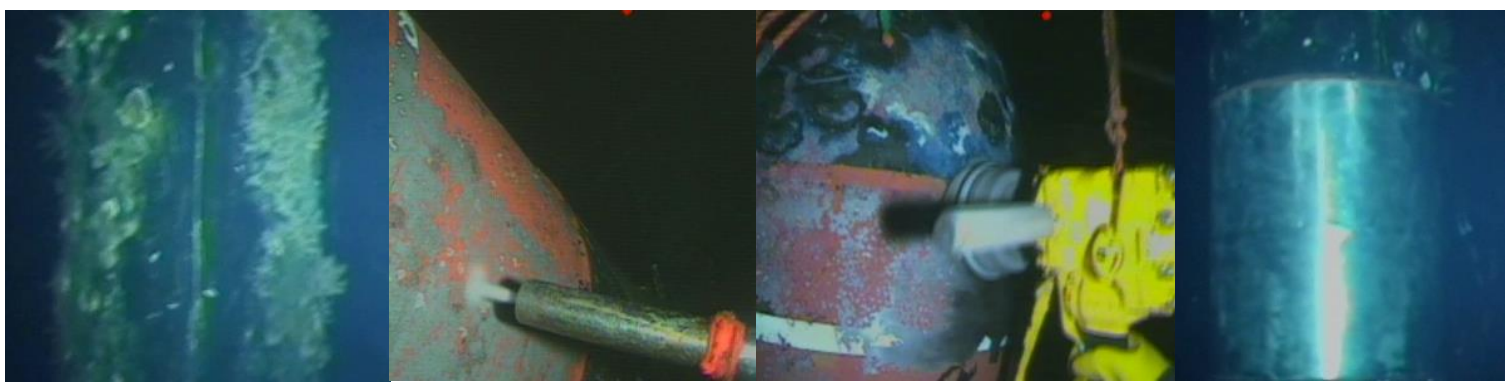

Figure 8. Tendon Preparation for Adhesive Clamp Bonding.

Once the tendon surface was prepared, divers applied epoxy to the interior of the clamp at the surface and descended for the installation at the pre-selected locations. As shown in Figure 9, the clamp is marked with a North facing direction. This alignment was critical to ensure that the bending modes can be detected.

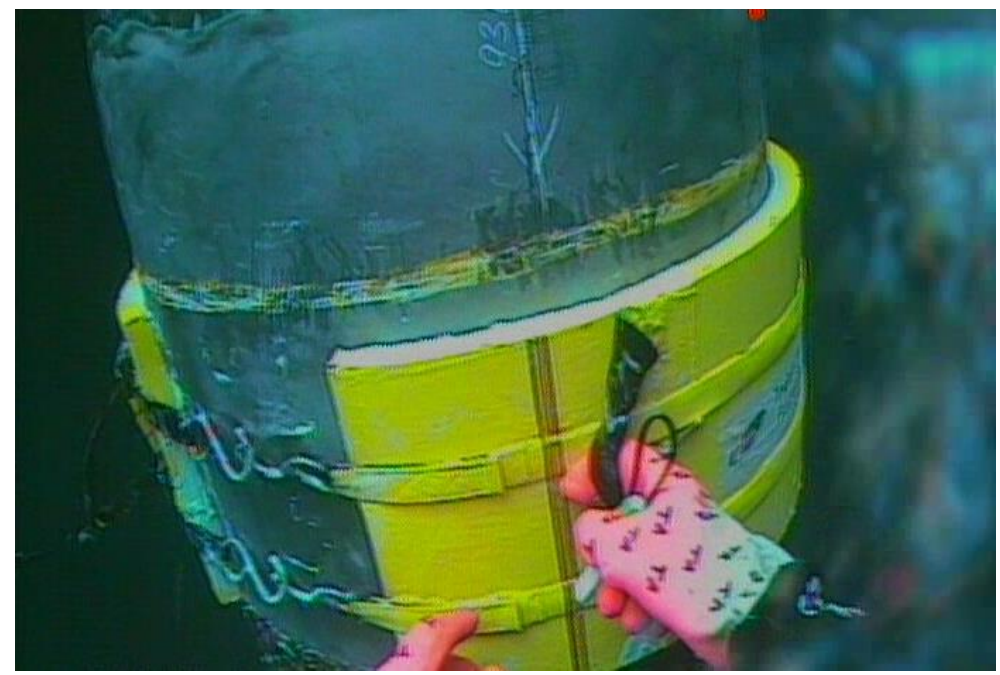

Figure 9. Installation of Adhesive Clamp on a TLP Tendon.

The installation of the clamp induces a slight stress on the strain sensors due to the mechanical forces encountered as the divers extend the clamp around the tendon and as the clamp is secured by the exterior tension bands. A challenge in calibration of the post installed sensors is determining the baseline or zero state of stress and correlating the sensitivity of the FBGs sensors on the clamp to actual load changes on the structure. The calibration of the monitoring system was enabled employing fundamental predictions of load to establish both baseline and sensitivity values. The sensitivity values were calculated through several tide cycles and correlated to predicted load levels at low and high tide values.

An additional issue with the fiber optic sensors is that any single break within the line has the potential to disrupt the light signal from the optical interrogator and render useless the monitoring system. A unique multiplexing method was incorporated with minimum cabling and connectors to make the system redundant and fault-tolerant to inadvertent cable damage. With this design, severing the cable in one location leads to no loss of data because the fiber optic cables form a loop. The loop can be interrogated from either direction as shown in the field termination box in Figure 10. 


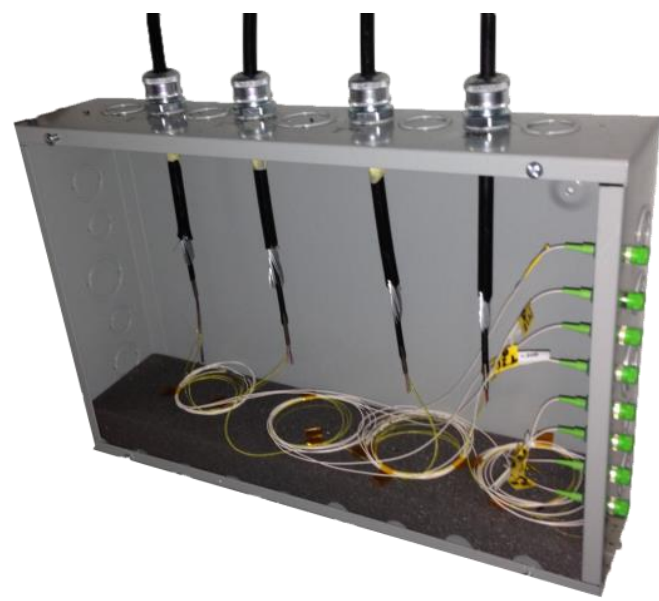

Figure 10. Field Termination Box with 4 Fiber Optic Cables and 8 Interrogation Lines.

Once the system was online and collecting data, some immediate observations were the sensitivity of the FBG sensors in detecting the effect of wave action on the platform. The noticeable 4-7 second wave period was observed in the time series data streaming into the control room as shown in Figure 11.

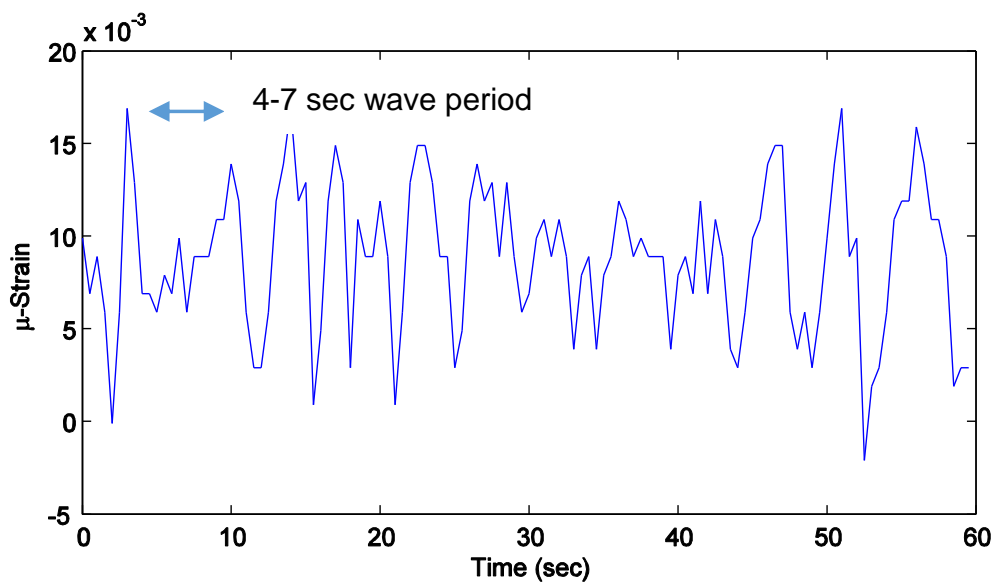

Figure 11. Sensitivity of the Fiber Optic Sensors as Shown by the Detection of Wave Action.

A Fast Fourier Transform (FFT) analysis was performed on the strain data to detect any resonant frequencies of the platform. The wave action appeared as a strong amplitude in the expected distribution of frequencies. One other observation from the frequency analysis was the appearance of a resonant heave frequency that is a known feature of the TLP design (11). The entire platform moves up and down at a much slower frequency than the wave action but much faster than the tidal action as shown in Figure 12.

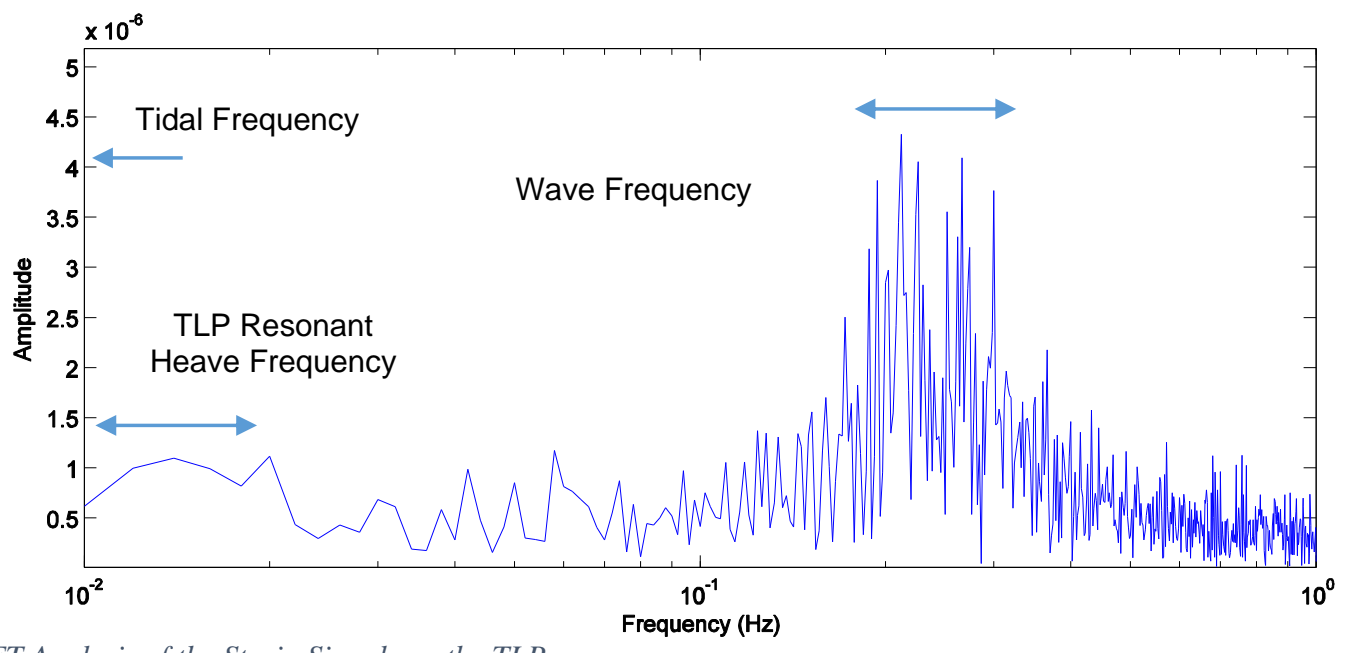

Figure 12. FFT Analysis of the Strain Signals on the TLP. 
A few other events observed after the installation of the tendon tension monitoring system were boat docking events, squall effects, crane movement, or other operations on the platform. A couple of the notable events are shown in Figure 13 with a noticeable lift on two of the tendons and a decrease on the load for the tendons on the opposite side of the platform. During the squall event, the tendons were trending up as the tide was increasing. During the boat docking event, the back of the boat was applying a lateral force to the platform as the reverse thrusters kept the boat up against the docking platform. In both cases, the sensitivity of the sensors allowed the operators to observe events that were previously undetectable.
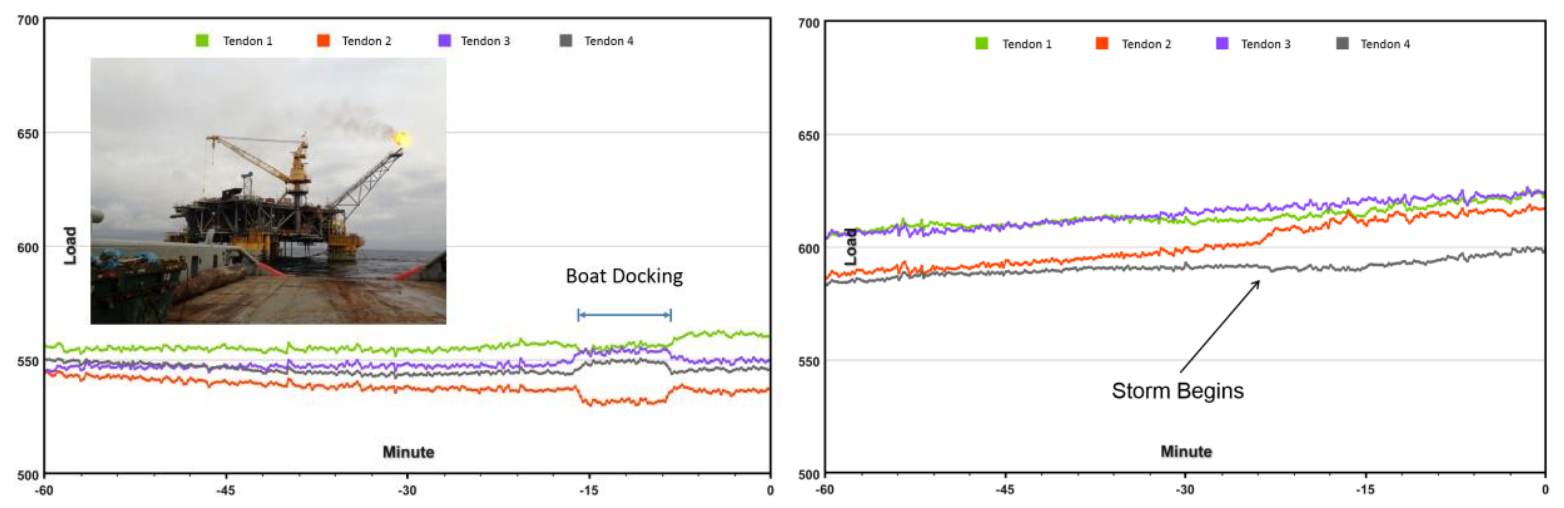

Figure 13. Boat Docking and Squall (Storm) Events.

One of the unexpected issues after installation was the presence of a thermocline at the 60' sensor location. This thermocline is the transition layer between surface and deep water levels. This level regularly moves up and down due to changes in the currents, tidal action, and other environmental factors. The change in temperature required the use of temperature compensation of the strain sensors. The changing temperature profiles were measured and analyzed at this moving boundary. A method to isolate temperature effects from structural data was developed and integrated into the software algorithm.
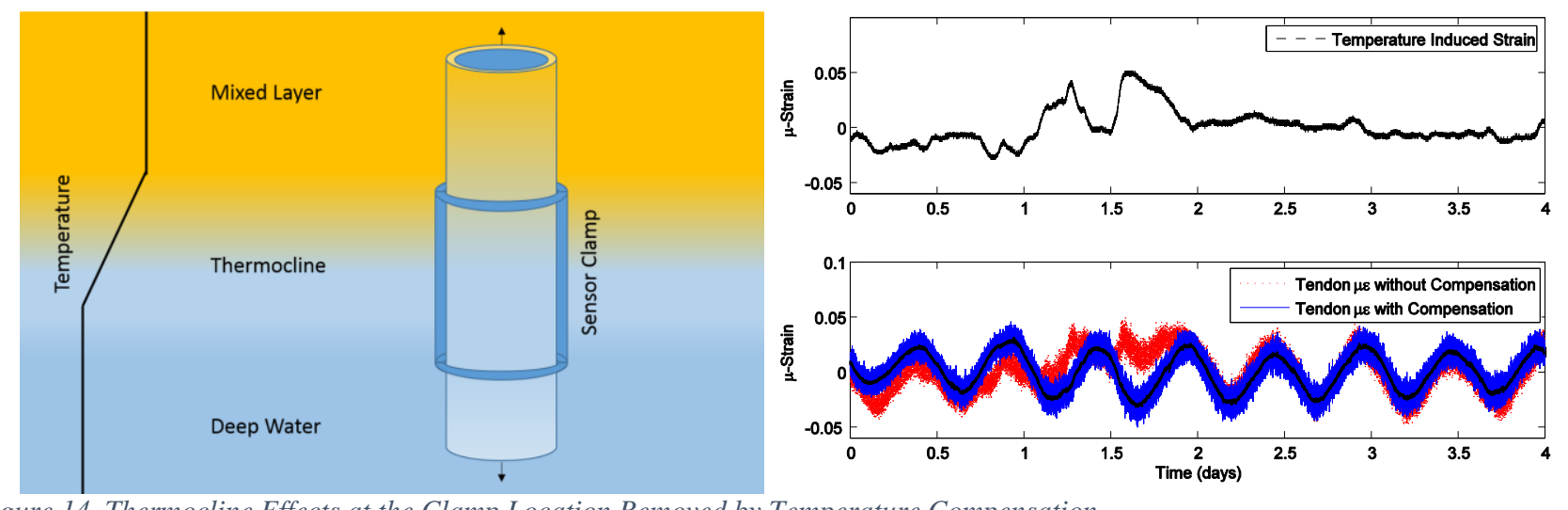

Figure 14. Thermocline Effects at the Clamp Location Removed by Temperature Compensation.

\section{Conclusion}

In development for more than two years, Clear Gulf is at a critical stage. Astro Technology has been collaborating with NASA, and have developed, tested and installed several groundbreaking technologies. The expanded goals for the project allow strong potential for private industry to contribute and benefit. This study relates recent progress on coupling of sensors to subsea structures, clamp design, calibration methods, and an implementation for tendon tension monitoring on a TLP.

\section{Nomenclature}

FBG Fiber Bragg Gratings

KIPS Units equal to $1000 \mathrm{lb}_{\mathrm{f}}$

ROV Remotely Operated Vehicle

TLP Tension Leg Platform

TTMS Tendon Tension Monitoring System 
VIV Vortex Induced Vibration

\section{Acknowlegments}

The authors acknowledge the contributions of NASA Johnson Space Center in Houston in generating the button pull test results and the 3-D printing of the prototype clamps. Several leading oil and gas companies have provided technical and financial leadership in the Clear Gulf Joint Industry Project (JIP).

Founded in the fall of 2010, Clear Gulf JIP supports extensive testing and further development of Astro Technology's advanced monitoring solutions, with critical input coming from experts at NASA as well as leaders within the industry. The project's technical steering committee includes representatives from participating companies. Participants are part of a highprofile effort to enhance safety and reduce environmental risk. The Clear Gulf steering committee will work with the Energy and Commerce Committee of the U.S. House of Representatives, the Bureau of Offshore Energy Management (BOEM), and the Bureau of Safety and Environmental Enforcement to ensure that systems support operators in meeting new offshore regulations.

\section{References}

[1] Brower, D., Abbassian, F., and Caballero, C., 2000. "Real-time Fatigue Monitoring of Deepwater Risers Using Fiber-Optic Sensors," Proceedings of ETCE/OMAE2000 Joint Conference: Energy for the New Millennium, New Orleans, LA. USA, February 14-17.

[2] Brower, D., Prescott, C., Zhang, J., Howerter, C., and Rafferty, D., 2005. "Real-time flow assurance monitoring with nonintrusive fiber optic technology", Proceedings of the Offshore Technology Conference, no. 17376.

[3] Brower, D. V., 2005. "Structural properties measurements in deepwater oil and gas fields using an advanced fiber-optic sensor monitoring system", Society for the Advancement of Material and Process Engineering (SAMPE).

[4] Brower, D., 2003. "Real-time fatigue monitoring of deepwater drilling and oil production risers using fiber-optic sensors", Structural Health Monitoring Conference, Palo Alto, CA.

[5] Brower, D., Hedengren, J., Asgharzadeh Shishivan, R., and Brower, A., 2013. "Advanced Deepwater Monitoring System”, In Ocean, Offshore \& Arctic Engineering OMAE, Nantes, France, no. 10920.

[6] Hedengren, J., Brower, D., and Mojica, J., 2012. “Advanced process monitoring of flow assurance with fiber optics”. In AIChE Spring Meeting.

[7] Brower, D., and Prescott, C., 2004. "Real time subsea monitoring and control smart field solutions", Subsea Rio, 3 (1), Rio de Janeiro, Brazil.

[8] Prescott, C., Zhang, J., and Brower, D., 2005. "An ambient pressure insulated LNG pipeline for subsea environments", Proceedings of the Offshore Technology Conference, no. 17338.

[9] Robertson, J. and Pierce, B., "90 Billion Barrels of Oil and 1,670 Trillion Cubic Feet of Natural Gas Assessed in the Arctic", URL: http://www.usgs.gov/newsroom/article.asp?ID=1980\&from=rss_home, Accessed 13 Jan 2014.

[10] Brower, D., Hedengren, J., Loegering, C., Brower, A., Witherow, K., and Winter, K., 2012. "Fiber optic monitoring of subsea equipment". In Ocean, Offshore \& Arctic Engineering OMAE, Rio de Janiero, Brazil, no. 84143.

[11] E. Huse, "Resonant Heave Damping of Tension Leg Platforms", 1990, OTC 6317.

[12] Hedengren, J., 2014. “Advanced Process Monitoring” in Optimization and Analytics in the Oil and Gas Industry, Eds. Kevin C. Furman, Jin-Hwa Song, Amr El-Bakry, Springer’s International Series in Operations Research and Management Science. 


\section{Appendix A}

Table A1. Plan for Adhesion Testing

\begin{tabular}{|c|c|c|c|c|}
\hline Test Number & Test Articles & Test Type & Test Configuration & $\begin{array}{c}\text { No. of Repeat } \\
\text { / Cycle }\end{array}$ \\
\hline $\mathrm{T}-1-1$ & \multirow{3}{*}{$\begin{array}{l}\text { 4.5" OD x 0.237" } \\
\text { Wall x 36" Length } \\
\text { Pipes (Test Article } \\
\quad \# 1,2 \text {,and 3) }\end{array}$} & \multirow{3}{*}{$\begin{array}{c}\text { Tension to } 0.15 \% \\
\text { Strain }\end{array}$} & Pipe without Clamp & 10 \\
\hline $\mathrm{T}-1-2$ & & & Pipe with Friction Clamp & 10 \\
\hline $\mathrm{T}-1-3$ & & & Pipe with Adhesive Clamp & 10 \\
\hline $\mathrm{T}-2-1$ & \multirow{3}{*}{$\begin{array}{c}\text { 8.625" OD x 0.148" } \\
\text { Wall x 36" Length } \\
\text { Pipe (Test Article \# } \\
4,5 \& 6)\end{array}$} & \multirow{3}{*}{$\begin{array}{c}\text { Tension to } 0.15 \% \\
\text { Strain }\end{array}$} & Pipe without Clamp & 10 \\
\hline $\mathrm{T}-2-2$ & & & Pipe with Friction Clamp & 10 \\
\hline $\mathrm{T}-2-3$ & & & Pipe with Adhesive Clamp & 10 \\
\hline C-1-1 & \multirow{3}{*}{$\begin{array}{l}\text { 4.5" OD x 0.237" } \\
\text { Wall x 36" Length } \\
\text { Pipes (Test Article } \\
\quad \# 1,2 \text {,and 3) }\end{array}$} & \multirow{3}{*}{$\begin{array}{c}\text { Compression to } \\
0.15 \% \text { Strain }\end{array}$} & Pipe without Clamp & 10 \\
\hline C-1-2 & & & Pipe with Friction Clamp & 10 \\
\hline C-1-3 & & & Pipe with Adhesive Clamp & 10 \\
\hline C-2-1 & \multirow{3}{*}{$\begin{array}{c}\text { 8.625" OD x 0.148" } \\
\text { Wall x 36" Length } \\
\text { Pipe (Test Article \# } \\
4,5 \& 6)\end{array}$} & \multirow{3}{*}{$\begin{array}{c}\text { Compression to } \\
0.15 \% \text { Strain }\end{array}$} & Pipe without Clamp & 10 \\
\hline C-2-2 & & & Pipe with Friction Clamp & 10 \\
\hline C-2-3 & & & Pipe with Adhesive Clamp & 10 \\
\hline B-1-1 & \multirow{9}{*}{$\begin{array}{c}8.625 " \text { OD x } 0.148 " \\
\text { Wall x } 120 " \text { Length } \\
\text { Pipe (Test Article \# } \\
7 \text { ) }\end{array}$} & \multirow{9}{*}{$\begin{array}{l}\text { 4-Pt Bending to } \\
0.15 \% \text { Strain }\end{array}$} & Pipe without Clamp at $0^{\circ}$ & 10 \\
\hline B-1-2 & & & Pipe without Clamp at $30^{\circ}$ & 10 \\
\hline B-1-3 & & & Pipe without Clamp at $45^{\circ}$ & 10 \\
\hline B-1-4 & & & Pipe without Clamp at $90^{\circ}$ & 10 \\
\hline B-1-5 & & & Pipe without Clamp at $135^{\circ}$ & 10 \\
\hline B-1-6 & & & Pipe without Clamp at $180^{\circ}$ & 10 \\
\hline B-1-7 & & & Pipe without Clamp at $225^{\circ}$ & 10 \\
\hline B-1-8 & & & Pipe without Clamp at $270^{\circ}$ & 10 \\
\hline B-1-9 & & & Pipe without Clamp at $315^{\circ}$ & 10 \\
\hline B-2-1 & \multirow{9}{*}{$\begin{array}{c}8.625 " \text { OD x } 0.148 " \\
\text { Wall x } 120 " \text { " Length } \\
\text { Pipe (Test Article \# } \\
8)\end{array}$} & \multirow{9}{*}{$\begin{array}{l}\text { 4-Pt Bending to } \\
0.15 \% \text { Strain }\end{array}$} & Pipe with Friction Clamp at $0^{\circ}$ & 10 \\
\hline B-2-2 & & & Pipe with Friction Clamp at $30^{\circ}$ & 10 \\
\hline B-2-3 & & & Pipe with Friction Clamp at $45^{\circ}$ & 10 \\
\hline B-2-4 & & & Pipe with Friction Clamp at $90^{\circ}$ & 10 \\
\hline B-2-5 & & & Pipe with Frictiont Clamp at $135^{\circ}$ & 10 \\
\hline B-2-6 & & & Pipe with Friction Clamp at $180^{\circ}$ & 10 \\
\hline B-2-7 & & & Pipe with Friction Clamp at $225^{\circ}$ & 10 \\
\hline B-2-8 & & & Pipe with Friction Clamp at $270^{\circ}$ & 10 \\
\hline B-2-9 & & & Pipe with Friction Clamp at $315^{\circ}$ & 10 \\
\hline B-3-1 & \multirow{3}{*}{$\begin{array}{l}8.625 " \text { OD x } 0.148 " \\
\text { Wall x } 120 " \text { Length } \\
\text { Pipe (Test Article \# } \\
9)\end{array}$} & \multirow{3}{*}{$\begin{array}{l}\text { 4-Pt Bending to } \\
0.15 \% \text { Strain }\end{array}$} & Pipe with Adhesive Clamp at $0^{\circ}$ & 10 \\
\hline B-3-2 & & & Pipe with Adhesive Clamp at $30^{\circ}$ & 10 \\
\hline B-3-3 & & & Pipe with Adhesive Clamp at $45^{\circ}$ & 10 \\
\hline
\end{tabular}




\begin{tabular}{|c|c|c|}
\hline B-3-4 & Pipe with Adhesive Clamp at $90^{\circ}$ & 10 \\
\hline B-3-5 & $\begin{array}{c}\text { Pipe with Adhesive Clamp at } \\
135^{\circ}\end{array}$ & 10 \\
\hline B-3-6 & $\begin{array}{l}\text { Pipe with Adhesive Clamp at } \\
180^{\circ}\end{array}$ & 10 \\
\hline B-3-7 & $\begin{array}{l}\text { Pipe with Adhesive Clamp at } \\
225^{\circ}\end{array}$ & 10 \\
\hline B-3-8 & $\begin{array}{l}\text { Pipe with Adhesive Clamp at } \\
270^{\circ}\end{array}$ & 10 \\
\hline B-3-9 & $\begin{array}{l}\text { Pipe with Adhesive Clamp at } \\
315^{\circ}\end{array}$ & 10 \\
\hline
\end{tabular}

